\title{
Poesia em estado de arquivo (Traduzir Dickinson)
}

Traduzir uma poeta como Emily Dickinson implica em inúmeros desafios, tarefas e desistências. O primeiro desafio, que o tradutor compartilha com os leitores, diz respeito à relação entre forma e sentido - relação que envolve múltiplas dimensões teóricas. 0 segundo, não menos significativo, tem a ver com distância e perspectiva. Na verdade, forma, sentido, distância e perspectiva se implicam mutuamente, e também necessitam de uma definição, ainda que breve, como a que vou fazer aqui. Trata-se de uma definição ad quo, pois se trata de uma poeta que jamais publicou seus poemas em livro, e mesmo os seus poucos poemas (dez, dos cerca de mil e oitocentos poemas) publicados em vida (em jornais e revistas) foram submetidos a decisões editoriais avessas à sua vontade. Em outros termos, a obra de Emily Dickinson já nasceu como arquivo, e o arquivo a determina enquanto forma.

Assim, entendo por forma, a totalidade material do texto, desde o manuscrito até a(s) sua(s) publicações, desde o papel, a costura das folhas, e evidentemente as palavras e acentos gráficos, a disposição deles no papel de acordo com critérios gráficos, sintáticos e prosódicos. No caso de Dickinson, isso implica também em saber se há ou não um manuscrito original, ou se se trata de uma transcrição de terceiros de um poema dela (o que acontece muitas vezes). As três edições críticas da obra de Dickinson em circulação (1955, 1997, 2016), respectivamente de Johnson (J), Franklin (F) e Miller (M), apresentam diversas informações sobre os manuscritos, sobre a provável data de redação, sobre os destinatários a quem os poemas foram enviados (quando o foram), e o Emily Dickinson Arquive (https://www.edickinson.org/) exibe a maioria dos manuscritos digitalizados, com metadados e com a transcrição diplomática dos textos. 
É nesse sentido que o conceito de forma na poesia de Dickinson já implica de cara as múltiplas dimensões do arquivo. Quem lê um poema de Dickinson lê um poema de Dickinson já filtrado por um procedimento editorial de seleção, por uma ordenação, por um método de transcrição, por um tipo de disposição gráfica. E não são poucas as diferenças entre uma e outra edição. Isso sem contar as mais de 43 milhões de referências e transcrições de poemas de Dickinson na internet (pesquisa no google em 18 de agosto de 2021). Ou seja, se na obra de Dickinson é delicado falar de um "original”, o que se dirá das traduções?

Ora, o tradutor de Dickinson também deve levar em conta o estado de arquivo dessa obra, considerando aquilo que está implicado em qualquer arquivo: por um lado, a relação de poder, de direitos (de publicação e reprodução), de acesso (por exemplo, aos manuscritos originais), que é intrínseca aos textos enquanto objetos materiais; por outro, a possibilidade de serem infinitamente abertos e reabertos, de pressuporem infinitas "entradas" e "saídas". Assim, se a obra de Dickinson pudesse falar, ela falaria o que diz o seu famoso verso: "I dwell in Possibility", moro na Possibilidade.

Já a dimensão do sentido, ela envolve distância e perspectiva. Com raras exceções, não sabemos o que Dickinson pretendia dizer com seus poemas fora deles. Ela não elaborou um programa estético, um manifesto, não deu entrevistas, não participou de grupos literários, de revistas literárias ou de movimentos. Tudo o que temos dela são as cartas, nas quais ela se refere aos poemas sempre de modo ainda mais enigmático do que os próprios poemas. Nesse sentido, ela se distingue fortemente de seus contemporâneos (como Edgar A. Poe, que elaborou uma "filosofia da composição", ou Walt Whitman, que, em seus poemas, já diz exatamente o que, por que, e como ele escreve, como em "I sing the body electric") e de seus predecessores naturais, que Dickinson leu e releu: Emerson - autor de "The Poet" (1844) - e Elizabeth Barrett Browning, cujo longo poema narrativo Aurora Leigh (1856) desenvolve todo um programa estético para uso de mulheres escritoras e poetas.

Assim, a obra de Dickinson foi sendo interpretada, desde a primeira publicação póstuma de seus poemas (1891) e vem sendo interpretada de diferentes maneiras. Nos anos 1890, Dickinson era sempre lida pela ótica da poeta excêntrica e reclusa, que teria deixado poemas notáveis, mas ainda assim, incorretos gramaticalmente e pobres quanto às rimas. Pior do que isso, dirá um crítico dessa época, "as ideias dela cambaleiam e engatinham, mas não aprendem a caminhar"1 (Richards 2013: 312). Por volta de 1920, a recepção de sua obra passa por uma revisão profunda. Para os poetas do imagismo, como William Carlos Williams, ela é vista como precursora de uma visão objetivista e americana; e para os integrantes do New Criticism, ela será louvada como uma das grandes vozes da língua inglesa de todos os tempos, superando inclusive Emerson. Allan Tate, um dos expoentes da crítica modernista vê em Dickinson uma "tensão entre a abstração e a sensação" (Tate apud Sewall 1963: 21), equiparando-a a John Donne. Nos anos 1950, Austin Warren (conhecido entre nós por sua Teoria da Literatura, escrita com o estruturalista tcheco René Wellek), 
escrevendo a partir do impacto causado pela primeira edição crítica de T. H Johnson, situa Dickinson e Whitman como os grandes discípulos de Emerson, sendo que Whitman teria se apoderado das ideias de Emerson, ao passo que Dickinson teria assimilado e transformado a sua poesia, condensando-a com o uso de uma nova pontuação e sintaxe sem predecessores, ou seja, já modernas (Warren apud Sewall 1963: 104). No final dos anos 1970, Dickinson sobe ao palco do debate feminista, a partir de um célebre ensaio de Adrienne Rich ("Vesuvius at Home", 1976) e do polêmico livro de Camile Paglia (Sexual Personae: Art and Decadence from Nefertiti to Emily Dickinson, 1990), que deu origem a uma reação prolífica de Harold Bloom, em vários cursos em Yale e ensaios dedicados a Dickinson.

Desde a criação da Emily Dickinson International Society em 1986 e do Emily Dickinson Journal (1992) o volume de leituras críticas e textuais da obra de Dickinson não para de se multiplicar. A isso também se somam as traduções de suas obras para dezenas de idiomas. No Brasil, desde que foi traduzida por Manuel Bandeira (em 1928), a poesia de Dickinson já foi vertida centenas de vezes, e entre seus tradutores mais conhecidos estão poetas como Ana Cristina Cesar e Augusto de Campos. No ensaio “Dickinson Latina”, em vias de publicação no Oxford Hadbook Emily Dickinson (Miller/Sanchez-Eppler, 2022), analiso diversas traduções e adaptações de Dickinson nos países de língua portuguesa e espanhola, e procuro demonstrar que cada porta e cada época produz traduções distintas da poesia de Dickinson. Trata-se aí de uma questão de distância e perspectiva. Assim como os editores e os leitores, os tradutores "abrem" o arquivo Dickinson em busca daquilo que pretendem e necessitam.

Minha tradução da Poesia Completa de Emily Dickinson, em dois volumes, leva em consideração antes de mais nada esse estado de arquivo da obra da poeta de Amherst. A tradução está organizada de acordo com dois princípios teórico-textuais: a costura e a sutura.

A costura tem a ver com as escolhas editoriais, das quais o tradutor participa desde o início: a escolha do texto-fonte (a edição de Cristanne Miller), a divisão em dois volumes, a preparação das notas e de todo o paratexto (que não coincidem com o texto fonte), e a constante remissão, no ato de traduzir, tanto à consulta aos manuscritos e à fortuna crítica sobre os poemas quanto às diferentes traduções dos poemas (além das inúmeras traduções para o Português, consultei também as traduções ao francês, ao alemão, ao espanhol, e, eventualmente, ao russo).

A sutura se relaciona com o que não se fecha nos textos, ao que permanece aberto do ponto de vista do sentido. Trata-se aqui daquilo que permanece indeterminado no poema, seja porque há "lacunas" sintáticas, ou porque há deslocamentos lexicais, combinações estranhas de palavras e de termos que geram não apenas efeitos de polissemia, mas mal-entendidos, dissenções, divergências. Todos os leitores de Dickinson sabem que há sempre um quociente de indeterminação - ou um abismo - entre o que os poemas dizem e o que querem dizer. Ora, é justamente nessa indeterminação que os poemas vivem. A sutura é, portanto, um modo de tentar deixar o poema viver. Em ou- 
tros termos, o trabalho de sutura é o trabalho com o que não faz sentido. Quem costura, costura sobre a matéria morta (o texto). A operação da sutura é uma costura sobre o que ainda vive (o poema).

Vejamos dois casos. Apresento os "originais" seguidos da minha tradução (ambos do volume 2 da Poesia Completa, ainda inédita neste momento). O primeiro é um clássico, "I never saw a Moor." (F800;J1052;M532).

\author{
I never saw a Moor. \\ I never saw the Sea - \\ Yet know I how the Heather looks \\ And what a Billow be - \\ I never spoke with God \\ Nor visited in Heaven - \\ Yet certain am I of the spot \\ As if the Checks were given - \\ Eu nunca vi o Mar - \\ Eu nunca vi o Moor \\ Mas sei como é a Urze \\ E a Onda, posso supor- \\ Nunca falei com Deus \\ Nem ao Céu fui de viagem - \\ Mas sei que existe o lugar \\ Até tenho a Passagem - \\ c. 1864.
}

Esse poema foi traduzido por Manuel Bandeira em 1948, e incluído na sua Estrela da Vida Inteira (poesias reunidas). Não vou discutir aqui a tradução de Bandeira, ou as de Jorge de Sena, de José Lino Grünewald, de José Lira, ou de Ana Luísa Amaral, entre tantas outras. Antes de mais nada, interessa-me entender esse texto, que na edição de 1890, e nas de Johnson e Franklin, sofre alterações de pontuação: Johnson, por exemplo, conclui a primeira estrofe com um ponto final. Johnson e Franklin também discordam quanto à datação do poema: para Johnson o poema é de c. 1865, para Franklin (e para Miller) do início de 1864. Esses são dois anos decisivos para Emily Dickinson (que vão dos problemas oftalmológicos, praticamente à beira mar, ao fim da guerra civil), e determinar a sua datação tem implicações semânticas na relação entre as circunstâncias biográficas e a escrita (por exemplo, devido aos problemas oftalmológicos, Emily passa temporadas 
em Cambridge, perto do mar, entre janeiro e abril).

Também por questão de "costura", não traduzo a palavra "moor" (que Bandeira traduz por "campo de urzes", e que outros traduzem por "urzedo" ou "charneca”). Sabemos que Dickinson tinha uma obsessão botânica (ela chegou a fazer um herbário complexo, aos nove anos), e que sabia muito bem entender a relação entre os espécimes botânicos e seu bioma. Ora, como explico na nota, o "moor" é um tipo de bioma bastante úmido e rochoso característico de regiões altas na Inglaterra, e particularmente de Yorkshire, onde há, entre outras plantas gramíneas, abundância de urzes (heather). Mas o "Moor" também é a paisagem do romance Wuthering Heights, de Emily Brontë, uma das leituras preferidas de Dickinson, que nunca foi à Inglaterra. Desse modo, mantenho a palavra original, bem como procuro manter o esquema de rimas do poema, propondo uma solução possível também para a tradução do ritmo e da versificação dickinsoniana (o uso que ela faz do common meter, que a obriga a usar as inversões "know I" e "am I"). A tradução da palavra "check" também gera problemas de costura e de sutura. Manuel Bandeira a traduz por "guia", e José Lira (que havia traduzido "moor" por "mangue") entende que se trata de uma chave. Ora, a fortuna crítica já havia estabelecido há muito que "check" é o nome usado para passagem de transportes no século XIX. Traduzir "check" por passagem é, pois, uma maneira de garantir a concordância entre as circunstâncias de escrita e a fortuna crítica, dando ao leitor do poema traduzido mais segurança quanto à forma do poema. A isso chamo de costura.

Acho que o que está vivo no poema é a relação jocosa entre a credulidade e a incredulidade. Dickinson usa e abusa da lógica para levar o leitor a acreditar numa fé que ela parece ter, mas que, no fundo, permanece em suspenso. No final, a única certeza é a morte, mas a morte é apresentada como uma forma de "visita ao céu" (que eu traduzi por viagem, para rimar com passagem, porque de fato, viagem rima com passagem!). Claro que se perde na tradução a rima, bastante jocosa, entre "God" e "spot", mas, como a tradução é sempre um jogo de perde-e-ganha, consegui um jogo de rimas bastante dickinsoniano (slant rhymes) entre "Mar", "Moor" (lê-se muorr) e "supor".

Outro caso bastante interessante é o do poema "We play at Paste -" (F282, J. 320, M 531), que se lê a seguir:

\author{
We play at Paste - \\ Till qualified for Pearl - \\ Then, drop the Paste - \\ And deem Ourself a fool - \\ The Shapes, tho', were similar, \\ And our new Hands \\ Learned Gem Tactics \\ Practising Sands - \\ Fazemos de conta -
}




\author{
Que Contas são Pérolas - \\ No fim, adeus às Contas - \\ Admitimos, que loucas - \\ Parecidas até, as Formas- \\ Agora, as Mãos cheias \\ Com Táticas de Jóia \\ Praticando Areias -
}

\title{
c. 1865
}

Assim como traduzir "I never saw a Moor." depois de Manuel Bandeira é um desafio, traduzir "We play at Paste -" havendo lido a linda tradução de Augusto de Campos pode parecer um exercício vão e supérfluo, se não é um desrespeito! Mas quero pontuar que meu objetivo é totalmente distinto do de Augusto de Campos. Ao grande poeta concreto interessa selecionar o que lhe parece necessário para "personificar a Ur-cinderela da poesia moderna", como Augusto de Campos assinala em sua "Introdução à primeira edição" de Não sou ninguém. Ao contrário de Campos, não fiz uma seleção: traduzi os cerca de 1800 poemas, sem cortes. Isso é parte da minha costura, que pretende aproximar o leitor de uma visão total do conjunto de poemas, para que ele possa constituir o seu próprio paideuma.

Quanto ao texto fonte, Augusto de Campos, por usar a edição de Johnson, traduz a primeira versão do poema, de 1862 (figura 1), tal como este foi enviado a Thomas Wenthworth Higginson numa carta de 15 de abril de 1862. Já a versão transcrita por C. Miller, que eu reproduzo e traduzo aqui, foi copiada e guardada por Dickinson em seu armário por volta de 1865 (figura 2). Se o leitor consultar os manuscritos disponíveis no Emily Dickinson Archive, poderá ter uma ideia da diferença formal entre os dois manuscritos, inclusive a caligrafia, que mudou bastante em 1865 , quando os problemas de visão começaram a se agravar.

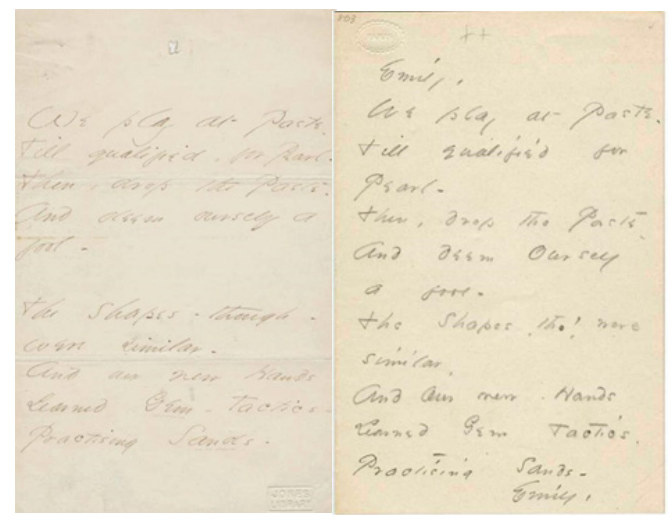

figura 1

figura 2 
Para além da forma gráfica, vale lembrar que o termo "Paste" pode significar pasta, argila ou o material (vidro e chumbo) usado para confeccionar bijuterias. Sabendo disso, entendemos o jogo entre o verdadeiro e o falso, ou melhor, entre o que uma criança considera "de verdade" e o que ela considera "de mentira". Penso na criança brincando, porque ela me ajuda a entender melhor o contexto, ou a circunstância do poema. Quando enviou esse poema a Higginson, Dickinson já vinha praticamente implorando que Higginson, o famoso editor do "suplemento literário" do Springfield Republican (que era mais ou menos a Folha de São Paulo de então) desse atenção a seus poemas, e os publicasse. Ela já havia tentado fazer isso com outro editor, Samuel Bowles, que também a ignorou. Bowles, aliás, só acabou publicando os poemas de Emily, anonimamente, porque a cunhada desta, Susan, Ihe pediu (e a série Dickinson da Apple revela acertadamente o que estava por trás da aceitação de Bowles). Mas Higginson não apenas ignorou o clamor de Emily. Ainda escreveu um ensaio no Republican intitulado "Carta a um/a jovem colaborador/a", em que dava conselhos sobre como deveriam ser os poemas enviados, sobretudo por mulheres, ao "suplemento" que ele dirigia com ares de grande poeta e crítico (que ele não era). Muitos desses conselhos, aliás, Higginson pilhou dos poemas que a própria Dickinson lhe enviava, e que ele jamais elogiou - a não ser depois da morte dela, arrependido. Vale lembrar enfim que, entre os anos de 1861 e 1865, Higginson publicou diversas vezes poemas de "jovens colaboradores/as", mas jamais publicou nada de Dickinson.

Assim, tendo em mente essa costura, podemos entender que o poema, mais do que metafísico, é literário, e descreve o "jogo" editorial tal como outro contemporâneo de Dickinson o fez, Herman Melville, em Pierre, or the ambiguities. Mas esse sentido - o literário - se depreende da distância e da perspectiva que temos do poema (a sua forma) no arquivo. Ignorar essa relação é supor que os textos existem soltos, como se estivessem numa nuvem, pairando no ar. Não me parece ser bem assim. 


\section{NOTAS}

* Adalberto Müller é professor da UFF, escritor e tradutor. Foi pesquisador visitante em Yale e no Instituto Leibniz/ZfL Berlin. Publicou recentemente o livro de contos $O$ traço do calígrafo (Editora Medusa) e a tradução anotada da Poesia Completa de Emily Dickinson (Editora da UnB/ Editora Unicamp). No prelo, está a sua retradução de Partido das coisas, de Francis Ponge (Iluminuras), além do livro de ensaios A imagem sob a imagem (Eduff).

${ }^{1}$ Todas as traduções não assinaladas são minhas.

\section{BIBLIOGRAFIA}

Dickinson, Emily (1995), The Complete Poems of Emily Dickinson. New York/London: Little Brown, 1955.

-- (1998), The poems of Emily Dickinson: variorum edition. Edited by R.W. Franklin Cambridge/ London: Belknapp/Harvard University Press.

-- (2015), Não sou Ninguém: poemas. Traduções de Augusto de Campos. 2a. edição revista e ampliada Campinas, Editora Unicamp.

-- (2016), Emily Dickinson's poems: as she preserved them. Edited by Cristanne Miller. Cambridge/London: Belknapp/Harvard University Press.

-- (2020), Poesia completa, v. 1, Os fascículos. Tradução e notas de Adalberto Müller. Brasília/ Campinas, Editora da UnB/Editora Unicamp.

Miller, Cristanne/Sanchez-Eppler, Karen (eds.) (2022), Oxford Handbook Emily Dickinson. Ed. Oxford, Oxford Press (no prelo).

Richards, Eliza (ed.) (2013), Emily Dickinson in Context. Cambridge; New York, Cambridge University Press.

Sewall, Richard B (1963), Emily Dickinson: a Collection of Critical Essays. Englewood, Prentice Hall. 